\title{
EPIGENETIC STUDY OF DNA METHYLATION IMPACT ON CHILDHOOD ASTHMA IN ZAGAZIG UNIVERSITY HOSPITALS
}

- Dina Mohamed Shokry: Professor of Pediatrics, faculty of medicine, Zagazig University, Egypt.

- Rabab Mohamed El-behedy: Prof. of Pediatrics, faculty of medicine, Zagazig University, Egypt.

- Amal Saeed Abd El-Azeem: Ass. Prof. of Medical Biochemistry, faculty of medicine, Zagazig University, Egypt.

- Mona Hamed Hasanin Jehad:Ass. lecturer of Pediatrics, faculty of medicine, Zagazig University, Egypt.

Received: 6 October 2018

Accepted: 20 December 2018

Corresponding author:Mona

Hamed Hasanin Jehad

01004274207

Mail:mona_jehad@yahoo.com

\section{ABSTRACT}

Background: Asthma is the most common chronic inflammatory disorder of the airways in children, with rising incidence during last few decades which brings heavy burden to the whole society. The underlying molecular mechanisms leading to asthma remain largely unclear. In complex diseases such as asthma, DNA methylation offers a potential mechanism for environmental modification of genetic responses.

Objective: Our study aimed to investigate the association of methylation at the ADRB2 promoter region with asthma development in Egyptian children and further effect on their level of asthma control.

Subjects and methods: Our case control study included 80 children, distributed as two groups: 64 asthmatics as cases and another 16 healthy children as control group. The cases were further sub-divided into three subgroups according the level of asthma control (based on GINA guidelines in 2015): 28 were well controlled asthmatics, 24 were partly controlled asthmatics and 12 patients were uncontrolled asthma. Blood-derived DNA samples from all children and assays of ADRB2 gene methylation was done using polymerase chain reaction. Pulmonary function testing, Skin prick testing and serum total IgE levels were measured using ELISA for all cases.

Results: The DNA methylation at ADRB2 promoter gene was significantly higher in the asthmatic children than in non-asthmatic group. Moreover, it was also higher in uncontrolled group in comparison to partly controlled and uncontrolled groups. Our data revealed a significant relationship between methylated DNA in patients with positive skin prick test and those receiving steroid therapy. ROC analysis revealed that methylated DNA can excellently differentiate asthmatic patients from healthy controls with AUC of 0.84 for DNA methylation. The optimal sensitivity and specificity to differentiate asthmatic children from controls were $(87.5 \%$ and $81.5 \%$ at a cutoff expression value >1). ROC analysis revealed that methylated DNA can differentiate uncontrolled or partially controlled asthmatic patients and controlled asthmatic patients with AUC of 0.891 for DNA methylation. The optimal sensitivity and specificity were $(86.1 \%$ and $89.3 \%$ at a cutoff expression value $>2.2)$.

Conclusion: our study suggested that increased methylation at the ADRB2 promoter area is associated with increased asthma susceptibility and poor asthma control which put it as a possible diagnostic and prognostic biomarker for asthma assessment in the near future.

Key words: Asthma, DNA methylation, ADRB2

\section{INTRODUCTION}

A sthma is one of the most serious allergic diseases and the most common chronic childhood disease in developed nations ${ }^{[1]}$

Although the incidences of most chronic illnesses have decreased over the last several decades, the prevalence and severity of childhood asthma have increased over the same time period ${ }^{[2]}$

Recent studies have suggested that; in addition to genetic variations, epigenetic alterations, such as aberrant DNA methylation patterns, may play a role in the development of asthma and asthma-related phenotypes ${ }^{[3]}$

Epigenetics is the study of mitotically heritable changes in phenotype (alterations in gene expression) that occur without direct alterations of the DNA sequence $^{[4]}$

Features of epigenetic mechanism mainly consist of DNA methylation, histone modification, and microRNAs ${ }^{[5]}$ 
DNA methylation is a biochemical to the $5^{\prime}$ position of the pyrimidine ring of cytosines lying next to a guanine, which is referred as $\mathrm{CpG}$ sites ${ }^{[6]}$

In complex diseases such as asthma, DNA methylation offers a potential mechanism for environmental modification of genetic responses, including those at the $\beta-2$ adrenergic receptor (ADRB2) gene locus ${ }^{[7]}$

The ADRB2 is a G-protein-coupled receptor present in respiratory epithelium, airway smooth muscle, and lymphocytes and is the principle target of beta-agonist bronchodilators ${ }^{[8]}$

The gene encoding the receptor ADRB2, has been extensively studied as a candidate gene for asthma susceptibility, asthma phenotypes, and response to medications ${ }^{[9]}$

A single previous study has shown a positive association of methylation of the ADRB2 gene with asthma severity in a cohort of Caucasian Children ${ }^{[10]}$

On reviewing other previous studies, none have examined such effect on asthma in the Egyptian population. This is important as populations may be affected by environmental, ethnic or racial specific modifiers, which has an influence on epigenetic effects. This study aims to determine the effect of DNA methylation at the ADRB2 promoter region on Egyptian asthmatic children.

\section{MATERIALS AND METHODS \\ Study design and setting:}

Our present study group consisted of 64 cases and 16 controls, who were recruited from the outpatient pediatric pulmonology clinic and inpatient ward, Department of Pediatrics, Zagazig University in Egypt. All the patients were diagnosed according to the Expert Panel Report (EPR) ${ }^{[11]}$

The study design was approved by the Zagazig University ethical committee. A written informed consent was obtained from the caregiver of each participant before the start of the study.

\section{Subjects and samples}

\section{Inclusion criteria :}

Asthmatic children, 5-15 years of age with clinically and spirometric-based diagnosis of asthma were included randomly process during which a methyl group is added at first in our study. Another nonasthmatic unrelated nonallergic age and sex matched control group with same ethnicity were selected randomly after completion of cases recruitment. Those patients were 15 years or younger which is the upper limit of care either in our pediatric pulmonology outpatient clinic or inward admission.

\section{Exclusion criteria:}

- Children younger than 5 years of age whose spirometric evaluation can't be assessed.

- Patients with severe co-morbidities e.g cancer, autoimmune diseases..etc

- Patients on systemic steroids

- Use of beta blockers

The cases were classified into three groups on the basis of asthma control level according to GINA guidelines ${ }^{[12]}$

\section{Sampling}

A total of $5 \mathrm{ml}$ venous blood was taken from each subject for further serological study.

\section{Data measurement}

Demographic, environmental and clinical and physical examination findings were recorded for all cases and controls included in the present study.

\section{Genotyping}

Detection of ADRB2 gene methylation using polymerase chain reaction (PCR) based restriction fragment length polymorphism (RFLP).

\section{Spirometry}

Pulmonary function tests were performed for all children using a fully computerized Spirometer (Jaeger MasterScreen $^{\mathrm{TM}}$ IOS, version 5.2 manufactured by VIASYS Healthcare GmbH, Hoechberg, Germany)

Pulmonary functions were assessed using forced expiratory volume in 1 second (FEV1), forced vital capacity (FVC) and the FEV1/FVC ratio, measured and expressed as a percentage of predicted values with a ratio higher than 0.9 being normal.

\section{STATISTICAL ANALYSIS}

SPSS version 24.0 was used for statistical analyses. According to the type of 
data, the following tests were used to test differences for significance:

- Differences between qualitative variables and percentages in groups were compared by Chisquare test.

- Differences between parametric quantitative independent groups by t-test, in nonparametric by Man Whitney and multiple by ANOVA

- Non parametric by Kruskal Wallace.
- Correlation by Pearson correlation

The significance level for all statistical tests was set at $P$ value $<0.05$.

\section{RESULTS}

This study was conducted from February 2015 to January 2016. 80 patients were included (64 cases and 16 controls) and their demographical characteristics are represented in Table (1)

Table 1 Demographic characteristics of studied groups

\begin{tabular}{|c|c|c|c|c|c|c|}
\hline Age & $\mathbf{N}$ & Mean & SD & \multicolumn{2}{|c|}{$\mathbf{T}$} & $p$ \\
\hline Cases & 64 & 8.6 & 2.7 & \multirow{2}{*}{\multicolumn{2}{|c|}{0.62}} & 0.54 \\
\hline Controls & 16 & 8.2 & 2.1 & & & \\
\hline Sex & Count & Cases & Controls & Total & $\mathbf{X}^{2}$ & $\boldsymbol{P}$ \\
\hline \multirow[t]{2}{*}{ Males } & $\mathbf{N}$ & 33 & 9 & 42 & \multirow[t]{6}{*}{0.11} & \multirow[t]{6}{*}{0.74} \\
\hline & $\%$ & $51.5 \%$ & $56.2 \%$ & $52.5 \%$ & & \\
\hline \multirow[t]{2}{*}{ Females } & $\mathbf{N}$ & 31 & 7 & 38 & & \\
\hline & $\%$ & $48.5 \%$ & $43.8 \%$ & $47.5 \%$ & & \\
\hline \multirow[t]{2}{*}{ Total } & $\mathbf{N}$ & 64 & 16 & 80 & & \\
\hline & $\%$ & $100 \%$ & $100 \%$ & $100 \%$ & & \\
\hline
\end{tabular}

The above table revealed that both groups were matched regarding their age and age with no statistically significant difference between both groups.

Table 2 Comparison between Serum levels of total IgE and peripheral eosinophils count in different studied groups.

\begin{tabular}{|c|c|c|c|c|c|c|}
\hline & Group & $\mathbf{N}$ & Median & IQR & $\begin{array}{c}\text { Man } \\
\text { Whitney } \\
\text { Z } \\
\end{array}$ & $P$ \\
\hline \multirow[t]{2}{*}{ IgE (IU/ml) } & Cases & 64 & 63 & $30.8-175.4$ & \multirow[t]{2}{*}{3.2} & \multirow[t]{2}{*}{0.011} \\
\hline & Control & 16 & 26 & $19-35.8$ & & \\
\hline \multirow{2}{*}{$\begin{array}{c}\text { Eosinophils(cell/ } \\
\mu \mathrm{I})\end{array}$} & Cases & 64 & 342,5 & $236.3-442.5$ & \multirow[t]{2}{*}{2.6} & \multirow[t]{2}{*}{$<0.001$} \\
\hline & Controls & 16 & 227.5 & $211.3-256.3$ & & \\
\hline
\end{tabular}

This table showed that the blood eosinophil count and total IgE levels were significantly higher in asthmatic patients than controls $(P<0.05)$.

Table 3 Comparison between quantitative expression of methylated DNA in different studied groups.

\begin{tabular}{|c|c|c|c|c|c|c|}
\hline & Group & N & Median & IQR & $\begin{array}{c}\text { Man } \\
\text { Whitney } \mathbf{Z}\end{array}$ & $\boldsymbol{P}$ \\
\hline $\begin{array}{c}\text { Methylated } \\
\text { DNA } \\
\text { expression }\end{array}$ & Cases & 64 & 2.4 & $1.7-2.8$ & 0.62 & $<\mathbf{0 . 0 0 1}$ \\
\cline { 2 - 6 } & Control & 16 & 0.67 & $0.59-0.78$ & & \\
\hline
\end{tabular}

This table showed that the quantitative expression of methylated DNA was significantly higher in asthmatic children than non-asthmatics $(P<0.05)$.

Table 4 Laboratory data of the asthmatic patients grouped according to the asthma control level

\begin{tabular}{|l|c|c|c|c|c|}
\hline Variables & Controlled & Partially & Uncontrolled & Significance & $P$-value \\
\hline
\end{tabular}




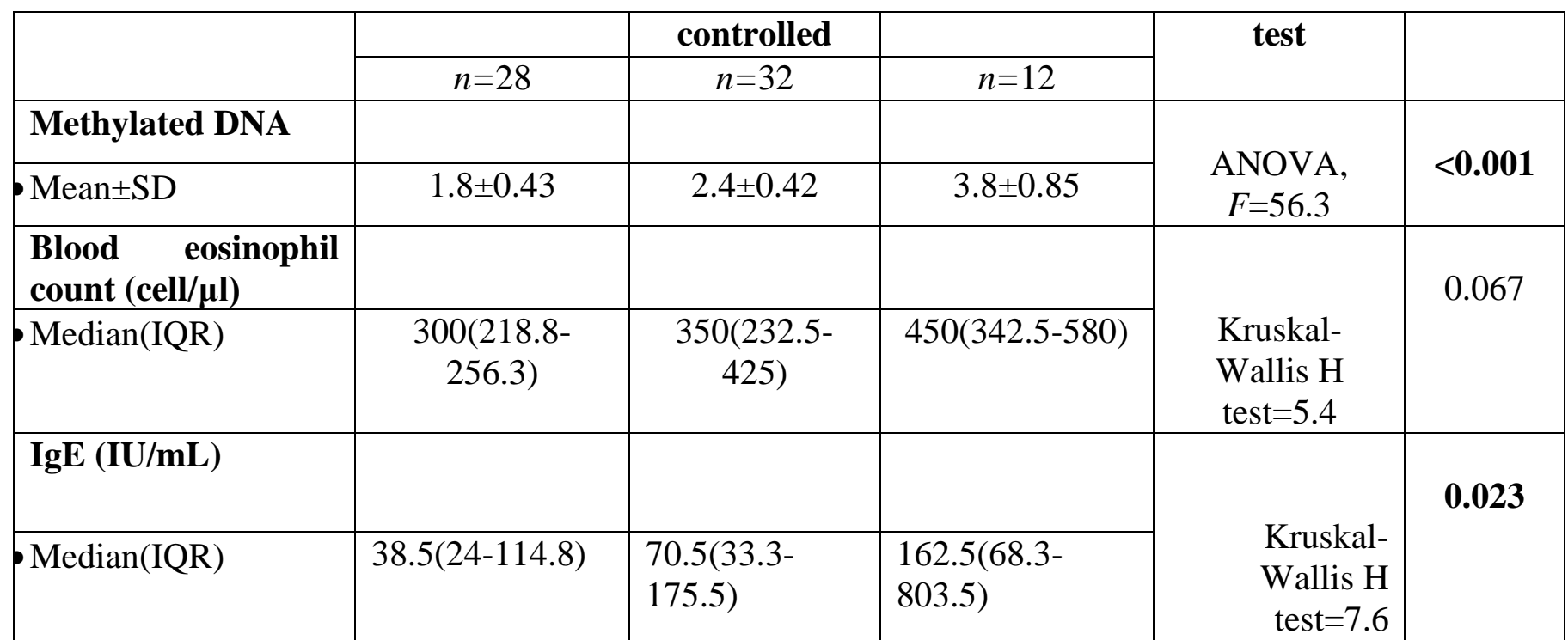

This table showed that the quantitative expression of methylated DNA and IgE levels were significantly different among asthmatic patients $(P<0.05)$. Blood eosinophil count was not significantly different among asthmatic patients $(P=0.067)$.

Table 5 Tukey post hoc test for comparison between controlled, partially controlled and uncontrolled asthmatic patients regarding the quantitative expression of methylated DNA

\begin{tabular}{|l|c|c|c|}
\hline \multicolumn{1}{|c|}{ Methylated DNA } & Controlled & Partially controlled & Uncontrolled \\
\cline { 2 - 4 } & $n=28$ & $n=24$ & $n=12$ \\
\hline \multicolumn{2}{|c|}{ Mean \pm SD } \\
\hline Controlled & $1.8 \pm 0.43$ & $2.4 \pm 0.42$ & $3.8 \pm 0.85$ \\
\hline Partially controlled & & $<\mathbf{0 . 0 0 1}$ & $<\mathbf{0 . 0 0 1}$ \\
\hline
\end{tabular}

This table showed that quantitative expression of methylated DNA was related to the asthma control level where it was significantly higher in partially controlled and uncontrolled patients than controlled patients $(P<0.001)$. Also, the quantitative expression of methylated DNA was significantly higher in uncontrolled patients than partially controlled patients $(P<0.001)$.

Table (6): Correlations between methylated DNA and laboratory data in asthmatic patients

\begin{tabular}{|c|c|c|c|}
\hline \multicolumn{2}{|c|}{ Variable } & $\begin{array}{c}\text { Blood eosinophil count } \\
(\text { cell/ } \boldsymbol{\mu l} \text { ) }\end{array}$ & IgE \\
\hline \multirow{2}{*}{ Methylated DNA } & $\boldsymbol{r}_{s}$ & 0.37 & 0.49 \\
\cline { 2 - 4 } & $\boldsymbol{P}$ & $\mathbf{0 . 0 0 3}$ & $<\mathbf{0 . 0 0 1}$ \\
\hline
\end{tabular}

This table shows a weak positive but highly significant correlation between the quantitative expression of methylated DNA and blood eosinophil count $(P=0.003)$. A reasonable positive but highly significant correlation between the quantitative expression of methylated DNA and IgE level $(P<0.001)$ was found.

A receiver operating characteristic (ROC) curve analysis: 
Figure (3): shows area under the receiver operating characteristic (ROC) curve for determine the cut-off point for methylated DNA to differentiate between asthmatic patients vs healthy controls

Figure (3): shows area under the receiver operating characteristic (ROC) curve for determine the cut-off point for methylated DNA to differentiate between asthmatic patients vs healthy controls

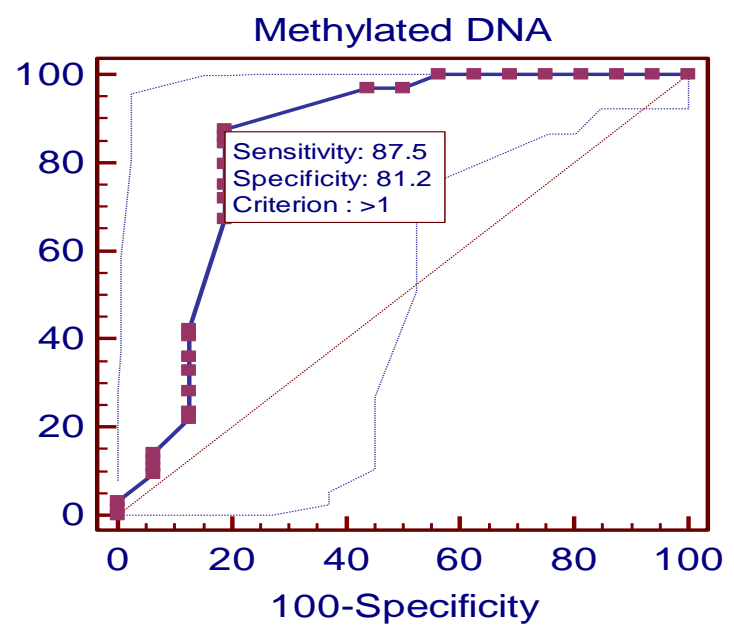

Figure 3 shows area under the receiver operating characteristic (ROC) curve for determine the cut-off point for methylated DNA to differentiate between asthmatic patients vs healthy controls

ROC analysis revealed that methylated DNA can excellently differentiate asthmatic patients from healthy controls with an area under the curve (AUC) of 0.84 for DNA methylation (95\% CI: 0.74 to $91, P<0.001$ ). The optimal sensitivity and specificity to differentiate asthmatic children from controls were $(87.5 \%$ and $81.5 \%$ at a cutoff expression value $>1)$.

This finding recommends that methylated DNA is a potential diagnostic biomarker in childhood asthma.

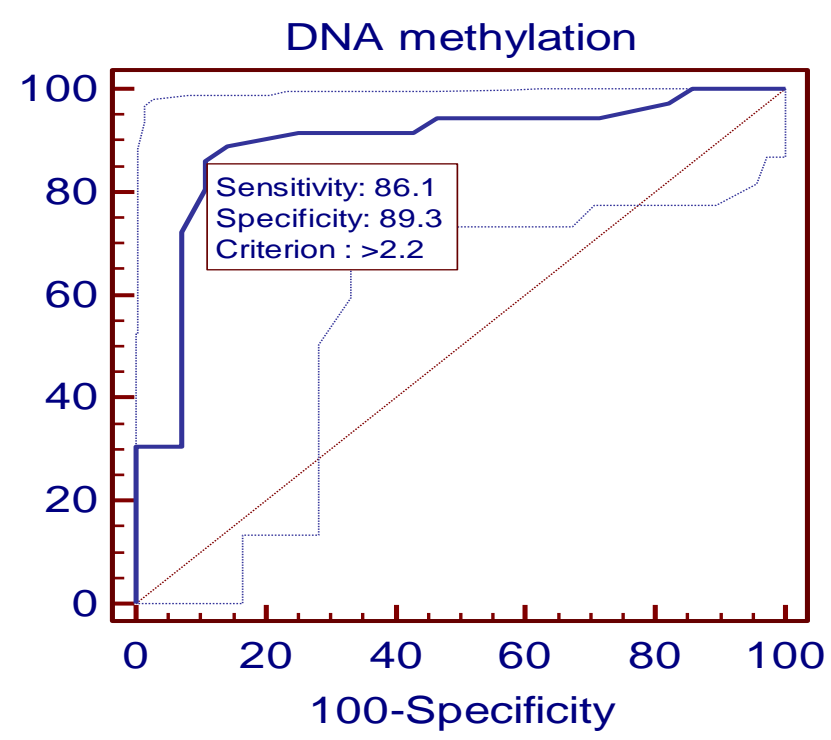

Figure 4 shows area under the receiver operating characteristic (ROC) curve for determine the cut-off point for methylated DNA to differentiate between uncontrolled or partially controlled asthmatic patients and controlled asthmatic patients.

$\begin{array}{lll}\text { ROC analysis revealed that } & \text { uncontrolled or partially controlled asthmatic } \\ \text { methylated } & \text { DNA can differentiate } & \text { patients and controlled asthmatic patients with }\end{array}$ 
an area under the curve (AUC) of 0.891 for DNA methylation (95\% CI: 0.79 to 0.96 , $P<0.0001)$. The optimal sensitivity and specificity were $(86.1 \%$ and $89.3 \%$ at a cutoff expression value $>2.2$ ).

This finding recommends that methylated DNA is a potential prognostic biomarker in childhood asthma.

\section{DISCUSSION}

Asthma is the most common chronic airway inflammatory disease of children. It is characterized by bronchial hyperresponsiveness which leads to remodeling and lastly intractable airflow obstruction ${ }^{[13]}$

The incidence of asthma is rising among children, which brings heavy burden to the whole society and results in huge medical expenditure all over the world. It is well-evidenced that asthma is a multi-factorial disorder caused by a complex interaction of genetic and environmental factors ${ }^{[14]}$

There is an underlying complex pathogenetic process which leads to the development of airway inflammation, bronchial hyper-reactivity, recurrent episodes of wheezing and dyspnea ${ }^{[15]}$

The increased prevalence of pediatric asthma is associated with modern lifestyle factors such as air pollutants and indoor contaminants and allergens thought to be influencing the increase ${ }^{[16]}$

As asthma development and progression are affected by environmental factors, a hypothesized role for epigenetic mechanisms has been proposed ${ }^{[17]}$

There has been particular interest in a role for DNA methylation, one of the most widely studied epigenetic mechanisms, which is known to be responsive to environmental exposures ${ }^{[18]}$

From this point of view, this study was held to verify the association of DNA methylation at the ADRB2 promoter region with asthma development in Egyptian children and its further effect on their level of asthma control.

To our knowledge, this is the first Egyptian study verifying the association of DNA methylation at the ADRB2 promoter region with asthma susceptibility and impact on disease course.
The elevated $\operatorname{IgE}$ production in asthmatic patients results in promotion of acute hypersensitivity responses, chronic eosinophil-predominant allergic inflammation with Th2 cells cytokine production ${ }^{[19]}$

Atopic asthma is influenced by genetic and environmental factors, and the level of atopy in particular is an inherited tendency, characterized by high non-specific $\mathrm{IgE}$ and/or high specific IgE against common antigens ${ }^{[20]}$

Eosinophilic inflammation is considered a characteristic of allergic asthma, which is more common in childhood than adulthood $^{[21]}$

In concordance with these data, our study revealed that the asthmatic group has higher levels of peripheral eosinophils $($ median $=342.5)$ and total $\operatorname{IgE}($ median $=63)$ in comparison to the non-asthmatic group (median eosinophils $=227.5$ and median total $\operatorname{IgE}=26)$.

These results are similar to those found by Antczak et al. in 2016, where higher levels of peripheral eosinophils and total IgE were observed in asthmatic group in comparison to non-asthmatics ${ }^{[22]}$ Another similar result was verified by Mishra et al., in 2011 where their study showed increased mean serum level of peripheral eosinophils and total IgE for cases of bronchial asthma in comparison to healthy control ${ }^{[23]}$

Our data revealed a significant positive correlation between DNA methylation and serum level of both peripheral eosinophils count and total $\operatorname{IgE}$ level

Our data revealed non-significant relationship between patients' age and gender and their state of DNA methylation ( $\mathrm{p}$ value 0.09 and 0.8 respectively)

Although the effect of age and sex has been examined in adults in several studies, few studies have reported on the effects of age on DNA methylation in children. Among adults, several studies have reported an inverse relationship between age and sex and methylation status with weak or no association with methylation ${ }^{[24]}$

Similar to our results, a number of studies focusing on methylation also found no 
relationship between age and sex and methylation state in children ${ }^{[25]}$

In the contrary to our study, Huen et al in 2014 had found a significant relationship of DNA methylation with host factors (age and sex) in children with decreased methylation among older age group and female children in comparison to younger age group and male patients ${ }^{[26]}$

According to Naumova et al in 2013 and in contrary to the above results, DNA methylation also varied with age and was higher in older males ${ }^{[27]}$

Lovinsky-Desir et al 2014 had also highlighted a significant age-, sex-differences in promoter methylation in allergic asthmatics [28]

Regarding DNA methylation at the promoter region of the ADRB2 gene, our study revealed significant difference between asthmatic children and non-asthmatics with increased DNA methylation in the cases (2.4) more than non-asthmatics (0.67).

Moreover, the ROC curve analysis revealed that hyper-methylated DNA has a diagnostic value in childhood asthma diagnosis with the optimal sensitivity and specificity to differentiate asthmatic children from controls were $87.5 \%$ and $81.5 \%$ at a cutoff expression value $>1$.

Our data revealed also that hypermethylated DNA was associated with poor asthma control where with an optimal sensitivity and specificity equal $86.1 \%$ and $89.3 \%$ at a cutoff expression value $>2.2$ which gives it a potential prognostic marker for childhood asthma.

These findings represent the successful identification of a possible epigenetic biomarker of asthma susceptibility and further outcome. They also indicate that seemingly very subtle changes in ADRB2 methylation may reflect large differences in phenotypic outcome.

The observation of effect between ADRB2 methylation and risk for severe asthma suggests its potential utility in providing important information on susceptibility to more severe asthma at multiple levels of methylation.

Our findings support the hypothesis that asthma development and severity may be affected by interactions between environmental and epigenetic factors.

Similar to our results, Fu et al in 2012 had concluded that increased ADRB2 methylation in blood was found to be associated with increased risk to develop asthma in children. Furthermore, DNA hypermethylation was associated with severe asthma exacerbations and poor asthma control suggesting its role as a potential prognostic biomarker for childhood asthma ${ }^{[10]}$

In airway smooth muscle, increased methylation of ADRB2 may lead to the reduced expression of the ADRB2 gene, which may compromise its ability to act as a mediator of airway relaxation and the body's response to both endogenous and synthetic b2-agonists ${ }^{[29]}$

Previous molecular and genetic studies have found that both ADRB2 expression and at least one ADRB2 genetic variant can alter bronchoreactivity to b2agonists ${ }^{[30]}$

Reduced response to b2-agonist as a result of the epigenetic down-regulation of ADRB2 expression may prompt the more frequent use of short-acting b2-agonists, which in turn may further compromise the effectiveness of b2-agonist treatment and lead to the exacerbation of asthma symptoms. Furthermore, studies of the effect of the use of the short-acting b2-agonist albuterol as monotherapy have shown that asthma control may deteriorate over time with regular use as opposed to intermittent use ${ }^{\text {[29] }}$

In the contrary to our results, Gaffin et al in 2014 had concluded that increased DNA methylation at the promoter region of the ADRB2 gene was associated with decreased asthma severity and improved asthma phenotypes and pulmonary function test (PFT) as measured by spirometry which provide evidence that epigenetic modification of the ADRB2 gene may directly influence the asthma course ${ }^{[31]}$

The current study enrolled a racially and ethnically diverse population and focused on methylation of the 5'UTR downstream of the transcriptional start site of ADRB2 gene in egyptian children while Gaffin et al focus on methylation at upstream region of the transcriptional start site of ADRB2 ${ }^{[31]}$ 
Another study by Gaffin and Phipatanakul in 2014 and in the contrary to our results had found that the increased methylation at the promoter region of the ADRB2 gene was inversely associated with asthma severity ${ }^{[32]}$

The association of DNA Hypomethylation and increased childhood asthma prevalence was documented by Yang et al $\mathbf{2 0 1 5}^{[33]}$

Such discrepancy between different studies may be attributed to ethnic differences, sampling differences and other factors that affect disease course between different populations ${ }^{[34]}$

The findings presented here are an important step in elucidating the relationship between methylation at the ADRB2 gene and clinical asthma phenotypes.

Vigorous investigation of epigenetic DNA modification of ADRB2 may offer the opportunity to discover new pathways in the disease and new pharmacologic targets ${ }^{[35]}$

Clarifying the role of epigenetic effects on the ADRB2 gene, as well as other candidate genes, allows for further understanding of complex asthma phenotypes by determining functional modifications to genomic expression.

We anticipate that integrative studies that explore the joint contributions of both genetic and epigenetic variations on phenotype will advance our understanding of complex diseases, particularly those with both significant genetic and environmental contributions, such as asthma.

\section{CONCLUSION}

Our results provide an evidence of an association between epigenetic changes in an established asthma candidate gene and increased risk to develop asthma among children. Increased ADRB2 DNA methylation in blood was found to be associated with increased risk for severe uncontrolled asthma in a population of children with active asthma.

\section{Study limitation:}

Our study was a single-center study (Zagazig University) with a relatively small sample size due to high cost concerning detection of DNA methylation, and so additional large-scale case-control studies are required to confirm our findings.

Other limitations includes that our analyses rely on the use of methylation data generated from peripheral blood leukocytes, which may not be the most appropriate tissue in which to study associations with asthma. Cells from other tissues may be more relevant, such as airway epithelial cells, buccal cells or cells from broncho-alveolar lavage.

\section{REFERENCES}

1- Palmer L and Cookson W. Genomic approaches to understanding asthma. Genome Res, 2000; 10:1280-87

2- Mannino DM, Homa DM and Pertowski CA. Surveillance for asthma-United States, 19601995. MMWR CDC Surveill Summ, 1998; 47:127

3- Morales E, Bustamante M and Vilahur N. DNA hypomethylation at ALOX12 is associated with persistent wheezing in childhood. Am J Respir Crit CareMed, 2012; 185:937-43

4-Goldberg AD, Allis CD and Bernstein E. Epigenetics: a landscape takes shape. Cell, 2007; 128:635-38

5- Lu Q. The critical importance of epigenetics in autoimmunity. J Autoimmun, 2013; 41:1-5

6- Jakopovic M, Thomas A, Balasubramaniam $S$ and Schrump D. Targeting the epigenome in lung cancer: expanding approaches to epigenetic therapy. Front Oncol, 2013; 3:261

7- Gaffin JM, Raby BA, Petty CR and Hoffman EB. $\beta-2$ Adrenergic receptor gene methylation is associated with decreased asthma severity in inner-city Schoolchildren. Clin Exp Allergy, 2013; 44: 681-89

8- Hawkins GA, Weiss ST and Bleecker ER. Clinical consequences of ADRb2 polymorphisms. Pharmacogenomics, 2008; 9:349-58

9- Litonjua AA.The significance of beta2-adrenergic receptor polymorphisms in asthma. Curr Opin Pulm Med, 2006; 12:12-17

10- Fu A, Leaderer BP, Gent JF, Leaderer D and Zhu Y. An environmental epigenetic study of ADRB2 5'-UTR methylation and childhood asthma severity. Clin Exp Allergy, 2012; 42:1575-81

11- National Asthma Education and Prevention Program (NAEEP), National Heart, Lung and Blood Institute, Expert Panel Report 3: Guidelines for the Diagnosis \& Management of Asthma.Summary report. J Allergy Clin Immunol, 2007; 120(5 Suppl):S94-138. 
12- Global Initiative for asthma. Global strategy for asthma management and prevention, 2008; available at www.Ginasthma.org. [accessed 09/11/2013]

13- Bandaru S, Marri K, Akka J, Alvala $M$ and Mundluru MP. Association of Transforming Growth Factor-Beta 1 Promoter Variant -509 C/T with Bronchial Asthma in South Indian Population Inflammation, 2015; 38(1): 409-14

14- Kauffmann $F$ and Demenais $F$. Geneenvironment interactions in asthma and allergic diseases: challenges and perspectives. J Allergy Clin Immunol, 2012; 130:1229-40.

15- Panek M, Pietras T, Fabijan A, Milanowski M, Wieteska L, Gorski $\mathbf{P}$ et al. Effect of glucocorticoid receptor gene polymorphisms on asthma phenotypes. Exp Ther Med, 2013; 5: 57280.

16-Mantzouranis E, Papadopouli E and Michailidi E. Childhood asthma: recent developments and update. Curr Opin Pulm Med, 2014 ; 20(1):8-16.

17-Bégin $P$ and Nadeau KC. Epigenetic regulation of asthma and allergic disease. Allergy, Asthma Clin Immunol, 2014; 10(1):1-12.

18-Lee $K$ and Pausova $Z$. Cigarette smoking and DNA methylation. Front Genet, 2013; 4: 132.

19- Hoffjan $\mathbf{S}$ and Ober C. Present status on the genetic studies of asthma. Curr Opin in Immunol, 2002; 14: 709-17.

20-Tavakkol AJ, Hosseini FR and Farahabadi HS. Association of the expression of IL-4 and IL-13 genes, IL-4 and IgE serum levels with allergic asthma. Iran J Allergy Asthma Immunol, 2007; 6: 67-72.

21- Possa SS, Leick EA and Prado CM. Eosinophilic inflammation in allergic asthma. Front Pharmacol, 2013;4:86-97

22-Antczak A, Domańska-Senderowska D, Górski P, Pastuszak-Lewandoska D, NielepkowiczGoździńska A, Szewczyk K et al. Analysis of changes in expression of IL-4/IL-13/STAT6 pathway and correlation with the selected clinical parameters in patients with atopic asthma. Int $\mathbf{J}$ Immunopathol Pharmacol, 2016; 29(2):195-204.

23-Mishra JK, Rashid P, Usha and Girish S. An Immunological Study of Bronchial Asthma with Special Reference to Interleukin-4, Interferon-ã and Immunoglobulin E. Indian J Allergy Asthma Immunol, 2011; 25(2): 91-96.

24-Zhu ZZ, Hou $L$ and Bollati V. Predictors of global methylation levels in blood DNA of healthy subjects: A combined analysis. Int J Epidemiol, 2012; 41:126-139.

25-El-Maarri $O$, Walier $M$ and Behne $F$. Methylation at global LINE-1 repeats in human blood are affected by gender but not by age or natural hormone cycles. PLoS ONE, 2011; 6:e16252.

26-Huen K, Yousefi P and Bradman A. Effects of Age, Sex, and Persistent Organic Pollutants on DNA Methylation in Children Environmental and Molecular Mutagenesis, 2014; 55:209-222

27-Naumova AK, Al Tuwaijri A and Morin A. Sex- and age dependent DNA methylation at the 17q12-q21 locus associated with childhood asthma Hum Genet, 2013; 132:811-22

28-Lovinsky-Desir S, Ridder $\mathbf{R}$ and Torrone $D$. DNA methylation of the allergy regulatory gene interferon gamma varies by age, sex, and tissue type in asthmatics Clinical Epigenetics, 2014; 6:9

29-Anderson GP. Current issues with beta2adrenoceptor agonists: pharmacology and molecular and cellular mechanisms. Clin Rev Allergy Immunol, 2006; 31:119-30.

30-Drysdale CM, McGraw DW and Stack CB. Complex promoter and coding region beta 2adrenergic receptor haplotypes alter receptor expression and predict in vivo responsiveness. Proc Natl Acad Sci USA, 2000; 97:10483-8.

31-Gaffin JM, Raby BA and Petty CR. beta-2 adrenergic receptor gene methylation is associated with decreased asthma severity in Inner-City School Children: asthma and rhinitis. Clin Exp Allergy, 2014; 44(5):681-89.

32-Gaffin JM and Phipatanakul W. Beta-2Adrenergic Receptor Methylation Influences Asthma Phenotype in the School Inner City Asthma Study Receptors Clin Investig, 2014; 1(1):1-12.

33-Yang IV, Pedersen BS and Liu A. DNA methylation and childhood asthma in the inner city. J Allergy Clin Immunol, 2015; 136: 69-80.

34-Kumar P, Kumar A and Misra S. Association of transforming growth factor-b1 gene C509T, G800A and T869C polymorphisms with intracerebral hemorrhage in North Indian Population: a case-control study. Neurol Sci, 2016; 37:353-59.

35-Cosio BG, Mann B and Ito K. Histone acetylase and deacetylase activity in alveolar macrophages and blood monocytes in asthma. Am J Respir Crit Care Med, 2004; 170:141-7

How to cite this article: Dina Mohamed Shokry DM, El-behedy RM, Abd El-Azeem AS. Epigenetic study of DNA methylation impact on childhood asthma in Zagazig University Hospitals. ZUMJ 2019; 25 (1): 92-100. 